\title{
A practice-oriented professional development program to support the introduction of a new mathematics curriculum in Portugal ${ }^{1}$
}

\author{
João Pedro da Ponte \\ Instituto de Educação, Universidade de Lisboa \\ jponte@ie.ul.pt
}

\begin{abstract}
This paper presents the extended workshop, a national professional development program that was used in the preparatory stages of the introduction of a new mathematics curriculum for basic education (grades 1-9) in Portugal. These workshops are based on five major ideas - orientation towards practice, focus on students' learning, collaboration, practitioner research, and change of professional culture. The evaluation shows that these workshops constituted a stimulating professional development setting that encouraged teachers to reflect about classroom practice and students' learning and was quite successful in supporting an overall movement favourable to the orientations of the new curriculum.
\end{abstract}

Kew words: Practice-based professional development, Collaboration, Practitioner research, School culture; Curriculum reform.

\section{Introduction}

An innovative new curriculum for basic education was approved by the Ministry of Education in Portugal in 2007 and became compulsory for the whole country in September of 2010 (ME, 2007). ${ }^{2}$ This paper presents the "extended workshop", a national professional development program that was used in the preparatory stages of the introduction of this curriculum. This initiative is based on five major ideas orientation towards teachers' professional practice, focus on students' learning, collaboration, teachers researching their own practice, and change of teachers'

\footnotetext{
${ }^{1}$ Ponte, J. P. (2012). A practice-oriented professional development programme to support the introduction of a new mathematics curriculum in Portugal. Journal of Mathematics Teacher Education, 15(4), 317327.

This paper is supported by national funds through FCT - Fundação para a Ciência e Tecnologia in the frame of the Project Professional Practices of Mathematics Teachers (contract PTDC/CPECED/098931/2008).

2 The team of authors of this curriculum included João Pedro da Ponte, Lurdes Serrazina (coordinators), Henrique Manuel Guimarães, Luís Menezes (mathematics educators), Ana Breda, Maria Eugénia Graça Martins (mathematicians), Fátima Guimarães, Hélia Sousa, and Paulo Alexandre Oliveira (mathematics teachers).

${ }^{3}$ In Portuguese "oficina de formação".
} 
professional culture. The paper presents an evaluation of this program and discusses the conditions that contributed to make this a successful professional development format.

\section{The Portuguese national mathematics curriculum for basic education}

The new national curriculum in Portugal emphasizes mathematical explorations assuming that such activities favour the students' involvement, provide multiple entry points for the mathematical activity of students at different achievement levels, stimulate holistic thinking, and reinforce learning elementary concepts (Ponte, 2007). Mathematical explorations form the basis of a style of teaching that we see in many other places around the world (Boaler, 1998; English, 2003; Lampert, 1990; Mason, 1991; Skovsmose, 2001). A distinctive feature of this curriculum is the way it strives to combine elements of its predecessor (dating from 1991), at the same time that it introduces important innovative features.

This curriculum indicates two main purposes for mathematics education: (i) to promote mathematics learning and the ability to use mathematics in different contexts, and (ii) to promote positive attitudes and appreciation of mathematics. The content is organized in four themes: Number and Operations, Geometry and Measurement, Algebra, and Data Handling. In Number and Operations it emphasises the development of numbers sense. Decimal numbers and fractions are handled in parallel. An important idea is that elementary school students must develop informal methods before introducing the standard operation algorithms. In Geometry the emphasis is on developing special sense and visualization as an intuitive knowledge of the environment and of the physical objects. Algebra was reintroduced as a curriculum theme, and algebraic ideas are stressed since the elementary grades in order to develop algebraic thinking. Generalization and working with symbols get important attention. In data handling, that includes probability, it is sought that students learn the basic processes of data collection and analysis, understand what a statistical investigation is, and develop a notion of random processes. In addition, the curriculum puts great emphasis in three main transversal capacities - problem solving, mathematical reasoning and mathematical communication - that must be continuously addressed while working on the four content themes.

In its methodological guidelines, the curriculum favours an exploratory approach. This means that the students must often work on tasks for which they do not 
have a ready process to find an answer. Their first step is to make sense of the task and to design a strategy to deal with it. Therefore, besides questions with clearly stated goals and conditions, such as exercises and problems, the students should also work on open situations, both in real life and mathematical contexts, which require extra attention in framing the questions and that may encourage the use of a variety of representations and strategies.

The supporting materials for the new curriculum indicate that this exploratory approach requires an appropriate classroom environment, in terms of structure, discourse and roles. One suggestion is to organize the lessons in three segments including the presentation and interpretation of the task, autonomous work of the students in pairs or small groups, and whole-class discussion. The lesson should conclude with a summary of the main ideas. The classroom discourse must encourage the contributions from students, who should be able to explain their strategies and responses and justify their claims.

\section{Theoretical perspective about professional development}

Practice oriented professional development. To be effective, professional development must have effects on teachers' professional practice and, therefore, professional development activities need to put practice in a central place (Ball \& Bass, 2003). However, much current teacher education only bears a thin relationship to professional practice. The assumption that teachers' knowledge and beliefs drive professional practice is convenient for teacher educators, as it is much easier to organize a professional development program based on theoretical issues than on practical problems. However, working at the level of knowledge (of mathematics, instruction, curriculum, students' learning, technology, educational issues...) does not equip teachers to change their practices, for example, adopting new curriculum orientations, selecting new kinds of tasks, creating new classroom environments and promoting dialogic communication. In fact, to learn mathematics, students need authentic and intense mathematics experiences and to reflect on these experiences and, in a similar way, to learn new ways of teaching, teachers need to try out new ways of work and analyse their consequences, share experiences with other teachers, reflect, and try again in a different way. 
Smith (2001) indicates different ways practice may be a part of a mathematics teacher professional development program. The first is professional development based on practice - recognizing the existing problems in the practical situations that teachers face and seeking to use theory to solve them. A second way is professional development situated in practice - materials that represent the teaching activity (such as mathematical tasks, samples of students' work, and classroom episodes) are used as opportunities for critique and investigation, assisting teachers in developing knowledge through the analysis of real situations. A third way is professional development based on teachers' own practice - teachers collect data from their practice and reflect on them, supported by the teacher educator and by the other teachers in the professional development program.

Focus on students' learning. In their activity, teachers are responsible to work in the framework of a mathematics curriculum and to honour the integrity of mathematics as scientific field of knowledge, presenting in an appropriate way the mathematical concepts, procedures, and representations and providing a comprehensive perspective about mathematics and its role in modern society. But they have to do this with close attention to students' learning. Such attention means to be able to diagnose students' prerequisite knowledge at the beginning of each new topic, especially the mathematical concepts, terms and representations, and as students' difficulties in learning new ideas and representations. It includes being able to take into account the ways students are used to communicate and understand the thinking that is behind what students actually say or write in order to set up moments of negotiation of meanings.

Therefore teachers are faced with the need to blend content and student learning (Murata, 2011). This means build on students' informal ideas, setting up tasks that take into account students' pre-existing knowledge and ideas, to promote their mathematical development and constantly monitor their progresses and possible difficulties. Teaching with a close attention to students' learning is quite different from teaching framed by a perspective of presenting mathematics to students in a correct, clear and motivating way. It implies looking for possible ways of integrating knowledge of mathematics with knowledge about the students - taking into account general perspective about learning processes and specific knowledge about students' culture and preferences as well as current mathematical understandings.

Collaboration. Joining together the efforts of several people is a powerful strategy to cope with complex problems, including many problems of professional 
practice (Peter-Koop, Santos-Wagner, Breen \& Begg, 2003). Several people working together have more ideas, more energy, and more capacity to overcome obstacles than an individual working alone, and they may build on the diversity of competencies (Hargreaves, 1994).

Two essential elements of a collaborative activity are the kind of organization and the relational atmosphere (Boavida \& Ponte, 2002). Reaching the aims of the collaboration may require some differentiation of roles between the members of the team. Such division of labour allows taking advantage of the interests and competencies of the different participants and facilitates the undertaking of a variety of tasks. The organization may evolve and assume new forms as the work progresses. The collaboration may become more intense as the participants get to know better each other and develop mutual confidence. That is, collaboration has an "emergent" nature.

The relational atmosphere presupposes an affective relationship among participants and involves dialogue, negotiation and care. The dialogue is necessary to establish a deep communication, yielding the comprehension of meanings and problems that each team member faces. The negotiation of meanings, objectives, and processes allows establishing platforms that allow for working together. And care involves a genuine attention to the problems and needs of the others. In addition, collaboration requires a certain level of mutuality in the relationship among participants, so that all give and receive something from each other.

Participants in a collaborative project need to adjust to each other, creating an efficient system of collective work. A heterogeneous group may become very creative but may also experience difficulty in finding a suitable working dynamic. Difficulties may develop at different levels, from the organization of the work, to the adjustment of conceptions and values of different members and to the negotiation of power relations within the group.

Teacher research. In the past, teachers' culture has been essentially that of "knowledge transmitting". Teachers tend to see their role as bridging the gap between scholarly knowledge and school students. However, today, this is clearly a narrow view of teachers' professional identity. Teachers remain as subject experts but are also professionals that face complex problems that, in many cases, require research to be understood and solved. Today, working on intervention projects and on local curriculum development projects is already part of the culture of many schools and many teachers 
participate in wider research projects or conduct research on their own initiative (Ponte, 2008).

Researching our own practice is a powerful way of learning. This happens in many professional fields, in which practitioners develop their ability to identify problems, gather information about them, consider the different sides of the issues, test solutions, analyse data, and interpret results. Such practitioners present their studies to the other members of the profession interested in the same problems. Doing this kind of research depends more on keeping an inquiry stance rather than on learning research methods (Cochran-Smith \& Lytle, 1999). The key element in this activity is knowing how to identify issues and problems, and learning about theoretical notions that help to interpret data and results.

Investigating is therefore becoming a new element of the teachers' professional culture. It requires the ability to integrate a view of theory and practice as two sides of a single coin. Establishing a dialogue between theory and practice is a major step towards understanding and solving professional problems. The teachers involved in researching their own practice carry out their projects, share their experiences, write papers, and present communications in professional meetings. This enables a deeper look at the experiences that become important resources for mathematics education, showing the path of curriculum development and change in professional practice.

There are many issues concerning the research that professionals carry out on their own practice (Zeichner \& Nofke, 2001). One of the most problematic is the validity issue - what counts as valid teacher research? These workshops were not concerned with that, but simply in using this approach as a learning experience for participants.

Change of the professional culture. There are many teachers who value exploratory activities and collaboration with other teachers. However, to become part of the professional culture those ideas need to be a mark of the work of schools, the institutional stance where teachers carry out their professional activity. In Portugal, there is a tradition of innovative projects carried out by collaborative groups of teachers and of sharing experiences in associative settings. In this country, like elsewhere, what is still missing is a continuous reflective and transformative activity at the school level (Sztajn, 2004). The professional culture of innovation is rather marginal and the mainstream professional culture of schools tends to be conservative. There is a long way to go until most mathematics teachers carry out their own curriculum projects 
within the schools, discussing the results with the other teachers, reflecting and stimulating further reflection, and developing a need to know more through different initiatives.

Teacher education based in the school and in the professional subject group may be carried out with many agendas. For example, it may involve a focus on the diagnosis of students' real difficulties, collaborative intervention projects with well-defined goals or self-learning within the group. In any case it will imply organization, joint planning, and exchange of experiences. The classroom and the subject group (or some of its formal subgroups) constitute fundamental action spaces and the starting point for professional development that aims to address not the "new ideas" that it are mandatory to know but the real students' struggles.

\section{The professional development program}

A teacher education challenge. The Portuguese official regulations for in-service professional development include a variety of possibilities, among which are the extended workshops. The standard format for such workshops is 25 hours of face-toface work plus up to 25 hours of participants' autonomous work, yielding 1 to 2 "professional credits". A distinctive feature of these workshops is that they must develop from practical activities and lead teachers to contact with materials that they may use later in their own classrooms. However, often these workshops mostly include lectures, readings, and assignments that promote little involvement from the participating teachers.

The Ministry of Education decided that a national program of such workshops should be developed as a first step towards the dissemination of the new curriculum. Given the time available for these workshops, a first decision was that they should aim to provide a flavour on some aspect of the new curriculum and not attempt to tell the whole story, overwhelming the participants with information. So, the goal of each workshop was to introduce the teachers into the major ideas of one of the curriculum mathematical themes. Therefore, workshops were organized for teachers of grades 5-6 and 7-8, corresponding to cycles 2 and 3 of basic education in the Portuguese school system, ${ }^{4}$ and also by theme - Numbers/Algebra (that were combined), Geometry, and

\footnotetext{
${ }^{4}$ There were no workshops for teachers of grades 1-4, since another national program was already in operation for these teachers.
} 
Data Handling. Another decision was to create a dynamic that would enable the participants to work with some intensity but also having plenty opportunity to reflect and consider the new ideas of the curriculum. So, each workshop was set up to last for 3-4 months and with a face to face working time of 25 hours. The teachers were supposed to work another 25 hours on autonomous way, in order to earn the full 2 "professional credits" for attending this professional development activity.

The structure and rationale for the workshops. Each workshop could be attended by up to 20 teachers and most of the work was done in small groups, usually of three to five members. The workshops were organized in six sessions of about four hours (usually on Saturday morning), held in three pairs: sessions 1-2 in the first month, sessions 3-4 in the second, and sessions 5-6 in the third. A schematic view of the whole activity is presented in table 1 .

Insert table 1 about here

The first session presented the plan of the workshop and also the new curriculum. Selected aspects of the curriculum documents were analysed, helping the participants to become familiar with them. In this session, most of the time was for work on sample tasks that illustrate the curriculum orientations on the workshop theme. Also, a lot of attention was given to the points in which there was new content, or changes in content or approach regarding the former curriculum. The teachers organized themselves in groups, according to their preferences. At the end of this session the participants were suggested to look for teaching materials aligned to the new curriculum for the workshop theme.

The second session was dedicated to the design by the participants of a lesson using tasks aligned with the new curriculum. They worked in practical tasks illustrating ideas from the curriculum and designed a sample lesson plan. The groups chose a topic to teach in a class and started identifying resources for this lesson. At the end of this session they were suggested to search more resources and received a classroom episode to read for the next session

In the third session the lesson plan was completed and the teachers designed strategies and instruments for data collection of classroom situations and students' work in their lesson. In the following weeks they used the tasks that they had constructed and collected data in one or more classes of members of the group. In many cases, one or two teachers carried out the lesson in their classes and the others acted as observers collecting data, sometimes using audio and video recording. 
In the fourth session the teachers had to reflect about the classes, analyse the data collected, and get started in organizing a presentation to all the whole group workshop participants. The presentation plan that was designed in this session was later completed by teachers, working on their own.

Then, the fifth and sixth sessions were dedicated to the presentation of the teachers' experiences, according to a suggested format. The final discussion was the critical moment of the workshop, as it was dependent on the quality of the experiences and of the reporting of the participants. In the end of the sixth session there was an evaluation of the whole activity and suggestions for further work.

The teacher educators for these workshops were fifty experienced mathematics teachers that undertook a two-day specific preparation for this activity. At the end of the first round of workshops, carried out in semester 1, the coordinators of this process worked with these teacher educators to reflect on their experience and discuss possible changes for the second round, carried out in semester 2. The teacher educators were encouraged to make personal adaptations to this format, but keeping the aims and general structure. In fact, some of them introduced significant personal variations in this format making wide use of the Moodle platform to organize materials and conduct discussion fora, emphasizing the search for resources and their sharing among participants, or proposing more readings, usually from the professional literature.

There were three rounds of such workshops that were voluntarily attended by some 2400 teachers (from an overall teacher population at grades 5-9 of about 8000 ). During this process, the main structure and philosophy of the workshops did not change, being strongly informed by an orientation towards teachers' professional practice, a close attention to students' learning, a permanent encouragement to collaboration, an orientation towards teachers researching on their own professional practice, and the change of the professional culture, in schools.

The evaluation process. The teacher educators responsible for each workshop had to provide a report, including the most salient aspects of this professional development activity with a special attention to the position of the participant teachers regarding the new curriculum orientations, their planning of classroom experiences, the presentation and discussion of these classroom experiences, and the overall structure and format of the professional development activity. This report should include in annex the materials elaborated by the participation teachers. Such reports and materials 
provided the data to elaborate a general evaluation of this program that was provided to the Ministry of Education, a summary of which is presented in the next section.

\section{The activity and evaluation of the workshops}

Actual tasks and samples of students' work were used in these workshops to exemplify the new curriculum orientations. Besides, new tasks were produced, were used in teachers' own classrooms, and were object of reflection and collective discussion. Therefore, there was a wide use of materials representing the professional activity of the teacher with a focus on student learning and teachers collected, reflected and discussed data directly emerging from their own practice. For most participants this was a completely new professional experience.

In addition, the teachers were presented the rationale for collaborative work and were encouraged to work in collaborative groups in order to carry out the relatively complex task that they were proposed and learn from each other. In consequence, most of the work was carried out in collaborative groups - planning tasks, constructing materials, observing classes, analysing data, and constructing a report. In some cases, some of the participating teachers had already some experience of collaborative work. In other cases, they found themselves grappling with the issue of working in a collaborative way. In the few cases in which the teachers could not join others in a group they worked individually with extra support from the teacher educators. These collaborative or precollaborative groups, with a few small crises, proved to be a fruitful arrangement appreciated by most participants.

In these workshops, participants experienced an informal introduction to practitioner research, as they framed a question (related to the efficacy of the lesson, tasks, and materials that they designed), organized a process of data collection, and reflected on the results. The final presentation and discussion were also an important moments of contrasting personal ideas and experiences and getting a professional sense how these fit in the new curriculum orientations. By doing this, they got a flavour of what it means to research their own practice, formulating questions, collecting data, analysing results, reporting findings, and raising new issues.

In the workshops, there was an encouragement towards the enrolment of groups of teachers from a single school and very often that was the basis for the groups that were organized. During the discussions, whenever the occasion allowed, mention was 
made to what could be made at the school level regarding the introduction of the new curriculum. In some cases, the final presentation made by teachers included proposals regarding the diagnosis of students' difficulties and possible initiatives to undertake at school level.

Naturally, the results of the workshops present considerable variation. Some teachers showed a clear support for the new orientations, with which they seemed to have already a high alignment, others showed interest in learning about these perspectives, and still others showed reservations. Teachers that were less attuned to the new curriculum orientations had more difficulty in making sense of the rationale behind exploratory tasks. But many others showed a high interest in trying out in their classroom the new curriculum perspectives. The prevailing atmosphere was that of involvement and interest, due to the highly practical nature of the workshops.

The workshop leaders reported that the activities were largely successful. The emphasis in practice, the work with materials directly related to the classroom activity and the collaborative setting were well accepted by most participants. The planning of the lesson that they felt should be exemplary as well as the collection of data and the setting up of a presentation created some concern in many participants, that considered these rather challenging activities, but they strived to correspond positively to what was proposed.

The reports of teachers regarding lessons that they planned and observed indicate a mixture of notions related to the new as well as to past curricula, but what is most salient is that they were very proud of the activities that they proposed in the classroom and the achievements of their students. In these reports we see the teachers' voices in a professional setting - of course with quite different levels of fluency giving lively images of classroom activity and students' thinking.

As it was expected, the most complex phase of the workshops was the final discussion of the experiences presented by the different groups. Many teachers are not used to participate in professional discussions and prefer to keep silent or just comment on points of detail or on side issues. There were a few reports from the teacher educators of discussions in which some teachers were aggressive with their colleagues. However, most reports indicated successful discussions and exchanges of experiences among groups of teachers in the program.

\section{Conclusion}


The introduction of the new mathematics curriculum in Portugal created an important agenda for professional development of which these workshops were only a small part. They were far from preparing teachers to teach according to the new curriculum - and that was not their aim. However, they were quite successful in creating an overall movement favourable to the new curriculum orientations. They also provided teachers with an opportunity to develop a stronger professional voice that articulates issues related to content to issues related to framing exploratory tasks and changing the classroom discourse in order to increase the opportunity of student participation.

The five orientations for teacher professional development previously indicated played a significant role in this initiative. The orientation towards teachers' professional practice is clear as teachers planned, taught and reflected in small professional groups and in larger groups about their classroom teaching. The close attention to students' learning is apparent as teachers were encouraged to report on students' oral interactions and on students' written productions on the mathematical tasks and were suggested to support their reflections on such materials. A permanent encouragement to collaboration was pervasive in this activity, as teachers worked in groups not just in the professional development sessions but also in the considerable amount of extra work that they carried out preparing their classes and the reports on their observations. The orientation towards researching professional practice was implied in the close attention to classroom events, to students' discourse, recording data, and to the need to make reflections and claims based on empirical evidence. The orientation to change the professional culture in schools was present in the encouragement to teachers to work with colleagues from the same school and also in the nature of the professional discourse promoted in the teacher education setting.

Some contextual factors also supported the success of this initiative. For example, the fact that it was a program organized by the authors of the curriculum, with the support of the Ministry of Education, for volunteer participants, and was led by experienced and recognized teachers may have contributed to its success. But the format, combining an orientation towards teachers' practices, focus on students' learning, collaboration, teachers' research, and change of the professional culture, combined with wide opportunities for professional discussion framed along innovative curriculum ideas, proved to be a fruitful design for professional development that may interest teacher educators around the world. 


\section{References}

Ball, D. L., \& Bass, H. (2003). Toward a practice-based theory of mathematical knowledge for teaching. In B. Davis \& E. Simmt (Eds.), Proceedings of the 2002 Annual Meeting of the Canadian Mathematics Education Study Group (pp. 3-14). Edmonton, AB: CMESG/GCEDM.

Boaler, J. (1998). Open and closed mathematics: Student experiences and understandings. Journal for Research in Mathematics Education, 29(1), 41-62.

Boavida, A. M., \& Ponte, J. P. (2002). Investigação colaborativa: Potencialidades e problemas. In GTI (Ed.), Reflectir e investigar sobre a prática profissional (pp. 43-55). Lisbon: APM.

Cochran-Smith, M., \& Lytle, S. L. (1999). Relationship of knowledge and practice: Teacher learning in the communities. Review of Research in Education, 24, 249305.

English, L. D. (2003). Engaging students in problem posing in an inquiry-oriented mathematics classroom. In F. K. Lester \& R. I. Charles (Eds.), Teaching mathematics through problem solving: Prekindergarten-grade 6 (pp. 187-198). Reston, VA: NCTM.

Hargreaves, A. (1994). Changing teaching, changing times: Teachers' work and culture in the postmodern age. London: Cassel.

Lampert, M. (1990). When the problem is not the question and the solution is not the answer: Mathematical knowing and teaching. American Educational Research Journal, 27(1), 29-63.

Mason, J. (1991). Mathematical problem solving: Open, closed and exploratory in the UK. ZDM, 91(1), 14-19.

ME (2007). Programa de Matemática do Ensino Básico. Lisboa: Ministério da Educação.

Murata, A. (2011). Introduction: Conceptual overview of lesson study. In L. C. Hart, A. Alston \& A. Murata (Eds.), Lessoan study research and practice in mathematics education: Learning together (pp. 1-12). New York, NY: Springer.

Peter-Koop, A., Santos-Wagner, V., Breen, C., \& Begg, A. (Eds.). (2003). Collaboration in teacher education: Examples from the context of mathematics education. Dordrecht: Kluwer.

Ponte, J. P. (2007). Investigations and explorations in the mathematics classroom. ZDM, 39(5-6), 419-430.

Ponte, J. P. (2008). Researching our own practice. In B. Czarnocha (Ed.), Handbook of mathematics teaching research (pp. 19-35). Rzeszów: University of Rzeszów.

Skovsmose, O. (2001). Landscapes of investigation. ZDM, 33(4), 123-132.

Smith, M. S. (2001). Practice-based professional development for teachers of mathematics. Reston, VA: NCTM. 
Sztajn, P. (2004). School-based community of teachers and outcomes for students. In M. J. Høines \& A. B. Fuglestad (Eds.), Proceedings of 28th PME Conference (Vol. 4, pp. 273-280). Bergen.

Zeichner, K., \& Noffke, S. (2001). Practitioner research. In V. Richardson (Org.), Handbook of research on teaching (pp. 298-330). Washington, DC. AERA. 